Our Nature (2009) 7:110-115

\title{
In Vitro Regeneration of Phyllanthus amarus Schum. and Thonn.: An Important Medicinal Plant
}

\author{
A. Sen*, M.M. Sharma, D. Grover and A. Batra \\ Plant Biotechnology lab. No.5, Department of Botany, University of Rajasthan, Jaipur. \\ *E-mail: antarasen_sible@yahoo.co.in
}

Received: 11.08.2009, Accepted: 08.11.2009

\begin{abstract}
An efficient in vitro plant regeneration protocol was developed for the medicinally potent plant species Phyllanthus amarus Schum. and Thonn. (Euphorbiaceae) using nodal segment as explant. Maximum multiplication of shoots (15.275 \pm 0.96$)$ was achieved on Murashige and Skoog's medium supplemented with BAP $(0.5 \mathrm{mg} / \mathrm{l})$ after 3-4 weeks of inoculation. The shoots were separated from cluster and subcultured for their elongation on the same medium. In vitro flowering was also observed on the elongated shoots after 3-4 weeks of sub culturing on the shoot elongation medium. In vitro rooting was obtained on half strength MS medium supplemented with IBA $(0.5 \mathrm{mg} / \mathrm{l})$. Regenerated plants were successfully hardened and acclimatized, $80 \%$ of plantlets survived well under natural conditions after transplantation.
\end{abstract}

Key words: In vitro regeneration, multiple shoots, nodal segments, Phyllanthus amarus

\section{Introduction}

Phyllanthus amarus Schum. and Thonn. commonly known as Bhui amla, kidney cleansing herb or stone breaker, is an herbaceous medicinally potent plant belonging to family Euphorbiaceace. This plant is distributed in all the tropical regions of the planet including India, Sri Lanka, China, Bahamas etc. It is a common kharif weed occurs both in cultivated field and wastelands. It has been traditionally used in the treatment of a variety of ailments including jaundice, asthma, ulcer, hepatitis, tuberculosis, malaria, dysentery, gonorrhea, syphilis, cough, diarrhea, vaginitis and urinary diseases and other hepatic disorders (Bharatiya, 1992; Unander, 1998). This plant is a favorite choice of the rural people because of its immense medicinal properties like antidote, against liver diseases, antiviral properties, antioxidant, heptoprotective, anti inflammatory and strong inhibitory effect against neurogenic (Thyagarajan et al., 1998; Kiemer et al., 2003; Chattopadhyay et al., 2006). These all medicinal properties are due to the presence of several natural compounds especially phyllanthin, hypophyllanthin, quercetin and $\beta$-sitosterol (Ishimaru et al., 1992; Calixto et al., 1998).

Overexploitation and population pressure have resulted large scale destruction of this plant from natural habitat. This is a seasonal plant due to which the continuous supply of this plant to the pharmaceutical companies is uncertain. Therefore, there is an urgent need to develop quick regeneration protocol to provide plant material for phytochemical and pharmacological analysis by various pharmaceutical companies. In the present 
research paper, we are providing a rapid and an efficient regeneration protocol of this potent medicinal plant.

Abbreviation: BAP-6-benzylaminopurine, IBA-indole-3-butyric acid, 2,4-D-2,4dichlorophenoxyacetic acid, Kn-6furfurylaminopurine, IAA-indole-3-acetic acid

\section{Materials and methods \\ Plant material}

Nodal segments $(0.5-1.5 \mathrm{~cm}$. long) were procured from 1-2 months old healthy mother plant growing in the Botanical garden, University of Rajasthan, Jaipur.

\section{Sterilization}

The picked nodal segments were kept under running water for about 15-20 minutes to remove soil particles and then rinsed with liquid detergent (Teepol 1\%) (v/v)) for 5-10 minutes. Then they were rinsed with sterile double distilled water at least thrice to get rid of teepol. Prior to inoculation, these explants were subsequently surface sterilized in the laminar air flow chamber with $0.1 \%$ mercuric chloride $\left(\mathrm{HgCl}_{2} ; \mathrm{w} / \mathrm{v}\right)$ for 2 minutes followed by repeated rinsing with sterile double distilled water.

\section{Culture media}

The surfaced sterilized explants were then aseptically inoculated on sterile MS medium (Murashige and Skoog, 1962) comprising $3 \%$ sucrose as carbon source and $0.8 \%$ agar as solidifying agent. The medium was also supplemented with various growth regulators [auxins- IAA (indole-3-acetic acid), IBA (indole-3-butyric acid), NAA, 2, 4-D (2, 4-dichlorophenoxyacetic acid) etc. and cytokinins- BAP(6-benzylaminopurine), $\mathrm{Kn}$ (6- furfurylaminopurine)] and $\mathrm{pH}$ of the medium was adjusted to 5.8 before autoclaving at pressure $1.06 \mathrm{Kg} / \mathrm{cm}^{-3}$. For multiple shoot induction different concentrations $(0.5,0.75,1.0,1.25,1.50$, $1.75,2.0 \mathrm{mg} / \mathrm{l})$ of BAP and $\mathrm{Kn}$ alone or in combination were used. However, various auxins such as NAA, 2, 4-D, IBA, IAA at different concentrations $(0.5$ to $8.0 \mathrm{mg} / \mathrm{l})$ were examined for in vitro root induction.

\section{Culture conditions}

The cultures were incubated at $25 \pm 2^{\circ} \mathrm{C}$ under cool, white and fluorescent light of 2000-2500 lux and relative humidity of

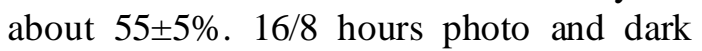
period were maintained in growth chamber, respectively. For each treatment, eight replicates were used and every experiment was repeated at least thrice. Data on multiple shoot induction; elongation and rooting were taken and statistically analyzed. Observations were recorded periodically.

\section{Induction of Multiple shoots}

The aseptic nodal segments were cultured on MS medium supplemented with 0.5 , $0.75,1.0,1.25,1.50,1.75,2.0 \mathrm{mg} / \mathrm{l}$ of BAP and $\mathrm{Kn}$ alone and/or in combination. Physiological conditions and number of shoots per explants were observed periodically. Maximum multiplication of shoots was noticed on MS medium congealed with BAP $(0.5 \mathrm{mg} / \mathrm{l})$. In vitro elongation was also attained on the same medium. In vitro flowering was also observed on MS medium supplemented with BAP $(0.5 \mathrm{mg} / \mathrm{l})$ on the shoots obtained prior to root induction.

\section{Establishment of Root cultures, Hardening and Acclimatization}

In vitro elongated shoots $(6-7 \mathrm{~cm}$.) with at least 3-4 nodes were taken out from the 
A. Sen, M.M. Sharma, D. Grover and A. Batra / Our Nature (2009) 7: 110-9

culture vials and transferred to half strength MS medium with different concentration $(0.5-8.0 \mathrm{mg} / \mathrm{l})$ of auxins like IBA, IAA, 2,4-D, NAA for root induction. The plantlets were taken out from culture vessel without damaging the delicate root system and rinsed with distilled water to remove adhering agar and then transferred to polycups containing vermicompost and autoclaved soil (1:3). Polycups were covered with inverted glass beakers to maintain high humidity and kept in culture chamber. They were gradually exposed from artificial environmental conditions to natural conditions for their acclimatization.

\section{Results and discussion}

During the present research investigation, maximum number of shoots $(15.275 \pm 0.96)$ was obtained when nodal explants inoculated on MS medium supplemented with BAP $(0.5 \mathrm{mg} / \mathrm{l})$ after 3-4 weeks (Figure 1). Further, increase in the concentrations of BAP decreased the number of multiple shoots (Table 1). Similar observations were reported in other plant species such as Phyllanthus urinaria (Kalidass and Mohan, 2009), Codiaeum variegatum (Nasib et al., 2008), Dictyospermum ovalifolium (Thoyajasksha and Ravishankar, 2001), Cunila galioides (Fracaro and Echeverrigaaray, 2001), Strawberry (Indra and Uppendra, 2000), Gymemma sylvestre (Komalavalli and Rao, 2000) and Vitex negundo (Sharma et al., 2006). Whereas, in contrast to the present results, Catapan et al. (2002) observed that $\mathrm{Kn}$ was proved to be the best for maximum shoot proliferation in Phyllanthus urinaria.

These multiple shoots were separated from the clump and subcultured on the same medium for their elongation in in vitro conditions. Elongation of shoots were also reported in other plant species like Costus speciosus, (Robinson et al., 2009) and Baliospermum montanum (Sasikumar et al., 2009) on the same medium in which they were initiated. However, in contrast to the multiplication medium, Datta et al. (2007) reported elongation of shoots on MS medium having different growth regulators in Jatropha curcas. After elongation, in vitro flowering was also observed in few shoots on the same medium incorporated with BAP (0.5 mg/l) (Figure 2).
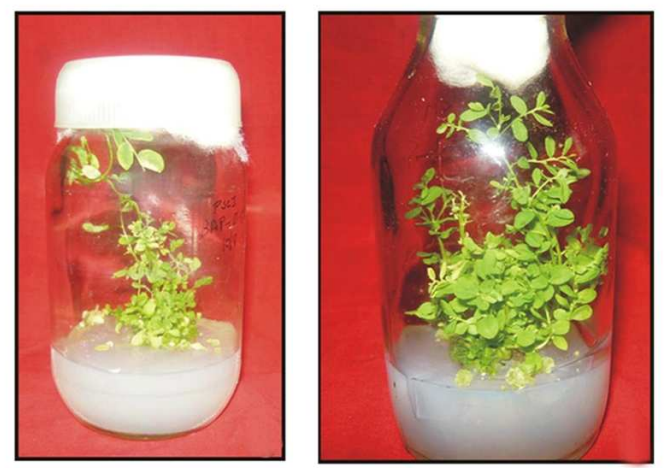

Figure1. Multiplication and elongation of Phyllanthum amarus shoot on MS medium supplemented with BAP $0.5 \mathrm{mg} / \mathrm{l}$.

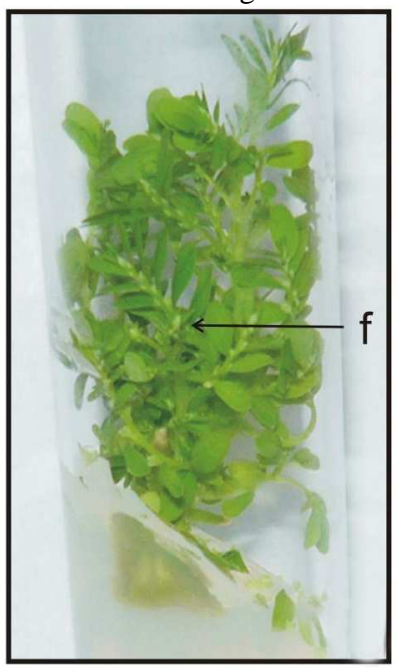

Figure 2. In vitro flowering on the same medium after 3-4 weeks of sub culturing (f-flower). 
A. Sen, M.M. Sharma, D. Grover and A. Batra / Our Nature (2009) 7: 110-9

Table1. Effect of cytokinin(s) on axillary bud proliferation in Phyllanthus amarus Schum. and Thonn.

\begin{tabular}{ll}
\hline Growth regulators $(\mathrm{mg} / \mathrm{l})$ & Nil \\
\hline Control $(0)$ & $15.275 \pm 0.96$ \\
BAP & $8.850 \pm 2.78$ \\
0.50 & $6.650 \pm 1.02$ \\
0.75 & $3.275 \pm 0.189$ \\
1.0 & $2.600 \pm 2.88$ \\
1.25 & $1.38 \pm 0.08$ \\
1.50 & $1.03 \pm 0.37$ \\
1.75 & \\
2.0 & $3.525 \pm 1.17$ \\
Kn & $2.975 \pm 2.88$ \\
0.50 & $2.600 \pm 2.88$ \\
0.75 & $1.875 \pm 0.83$ \\
1.0 & $1.325 \pm 0.89$ \\
1.25 & $1.00 \pm 2.16$ \\
1.50 & $0.110 \pm 0.12$ \\
1.75 & \\
2.0 & $2.325 \pm 2.92$ \\
\hline BAP + Kn & $1.625 \pm 0.85$ \\
$0.5+0.50$ & $1.250 \pm 0.18$ \\
$0.5+0.75$ & $0.750 \pm 0.88$ \\
$0.5+1.0$ & $0.580 \pm 0.13$ \\
$0.5+1.25$ & $0.5 \pm 0.20$ \\
$0.5+1.50$ & Nil \\
$0.5+1.75$ & \\
$0.5+2.0$ & Mean $\pm \mathrm{t}_{0.05}$ S. \\
\hline
\end{tabular}

*Values are 95\% confidence limits for Mean and mean values within the column followed by the same letter are not significantly different by the Tukey's test at $0.05 \%$ probability level

Table 2. Effect of various auxins on root induction in Phyllanthus amarus Schum. and Thonn.

\begin{tabular}{llll}
\hline $\begin{array}{l}\text { Auxin conc. } \\
(\mathrm{mg} / \mathrm{l})\end{array}$ & $\begin{array}{l}\text { Rooting response } \\
(\%)\end{array}$ & $\begin{array}{l}\text { Root length } \\
\left(* \text { Mean } \pm \mathrm{t}_{0.05} \text { S.E. }\right)\end{array}$ & Nemarks \\
\hline Control & 0 & & Nil \\
\hline IBA & & & Well developed root system, roots were \\
0.5 & 95 & $3.30 \pm 0.21$ & $\begin{array}{l}\text { healthy, branched, white in color and fast } \\
\text { growing having root hairs }\end{array}$ \\
1.0 & $65-70$ & $2.30 \pm 0.09$ & \\
1.5 & $40-50$ & $1.82 \pm 0.05$ & Roots developed were short, thin and \\
$2.0-8.0$ & Nil & & without root hairs. \\
\hline $2,4-\mathrm{D}$ & $30-40$ & $1.25 \pm 0.05$ & \\
0.5 & $20-30$ & $1.08 \pm 0.02$ & \\
1.5 & Nil & & No response \\
$2.0-8.0$ & Nil & & \\
\hline IAA \& NAA & & \\
$0.5-8.0$ & & & \\
\hline
\end{tabular}

*Values are $95 \%$ confidence limits for Mean and mean values within the column followed by the same letter are not significantly different by the Tukey's test at $0.05 \%$ probability level 
In vitro root induction was obtained when the elongated shoots were transferred on half strength of MS medium fortified with IBA $(0.5 \mathrm{mg} / \mathrm{l})$ (Table 2, Figure 3). IBA is more important plant growth hormone for the root induction in tissue culture. Omran et al. (2008) also noticed in vitro rooting on IBA in Lins culinaris Medik., which is in consonance to the present research work. In contrast to this, Catapan et al. (2000) reported that, NAA and IAA enhanced root proliferation in Phyllanthus caroliniensis.

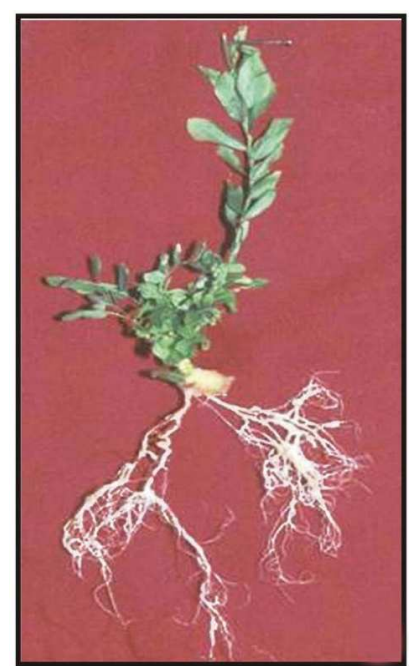

Figure 3. In vitro rooting on half strength $\mathrm{MS}$ medium containing $0.5 \mathrm{mg} / \mathrm{l}$ of IBA

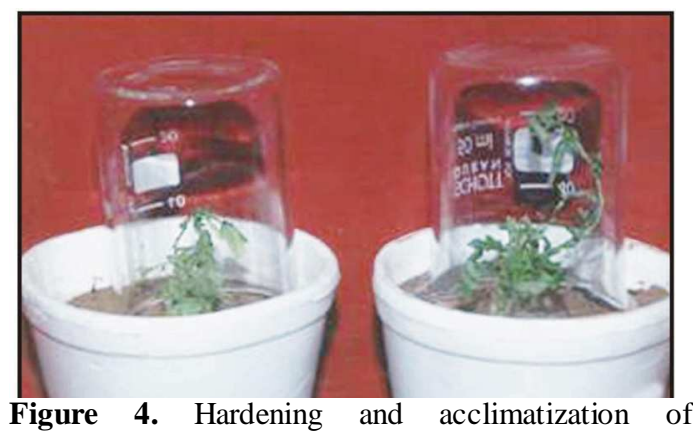

Figure 4. Harder
regenerated plants
In vitro raised plantlets were taken out from the culture bottle and hardening and acclimatization was done by the method described in "Materials and Methods" (Figure 4).

The present paper presents the protocol for large scale clonal propagation of $P$. amarus without any seasonal influences. However, other reports are also available on regeneration of this plant species, but they are not much efficient and taking more time as compared to the present protocol.

\section{References}

Bharatiya, V.B. 1992. Selected medicinal plants of India. Bombay. Tata Press. Pp. 253-257.

Calixto, J.B., A.R.S. Santos, F.V. Cechinel and R.A. Yunes 1998. A review of the plants of the genus Phyllanthus: Their chemistry, pharmacology and therapeutic potential. Med. Res. Rev. 18: 225-258.

Catapan, E., M. Luis, B. Da Silva, M.F. Netto and A.M. Viana 2002. Micropropagation, callus and root culture of Phyllanthus urinaria (Euphorbiaceae). Plant Cell Tiss. Org. Cult. 70(22): 301-309.

Catapan, E., M.F. Otuki and A.M. Viana 2000. In vitro culture of Phyllanthus caroliniensis (Euphorbiaceae). Plant Cell Ttiss.Org. Cult. 62: 195-202.

Chattopadhyay, P., S.S. Agrawal and A. Garg 2006. Liver regenerative effect of Phyllanthus amarus Linn. against alcohol induced liver cell injury in partially hepatectomised Albino Rats. International J. of Pharm. 2(4): 426-430.

Datta, M.M., P. Mukherjee, B. Ghosh and T.B. Jha 2007. In vitro clonal propagation of biodiesel plant (Jatropha curcas L.). Curr. Sci. 93: 10-25.

Fracaro, F. and S. Echeverrigaaray 2001. Micropropagation of Cunila galioides, a popular medicinal plant of south Brazil. Plant Cell Tiss. Org. Cult. 64: 1-4.

Indra, D.B. and D. Uppendra 2000. Micropropagation of Indian wild strawberry. Plant Cell Tiss. Org. Cult. 60: 80-83.

Ishimaru, K., K. Yoshimatsu, T. Yamakawa, H. Kamada and K. Shimomura 1992. Phenolic constituents in tissue cultures of Phyllanthus niruri. Phytochem. 34: 2015-2016. 


\section{A. Sen, M.M. Sharma, D. Grover and A. Batra / Our Nature (2009) 7: 110-9}

Kalidass, C., and V.R. Mohan 2009. In vitro rapid clonal propagation of Phyllanthus urinaria Linn. (Euphorbiaceae)- A medicinal plant. Researcher 1(4): 56-61.

Kiemer, A.K., T. Hartung, C. Huber and A.M. Vollmar 2003. Phyllanthus amarus has antiinflammatory potential by inhibition of iNOS, cox2 and cytokine via the NF-KB pathway. J. Hepatol. 38: 289-297.

Komalavalli and M.V. Rao 2000. In vitro micropropagation of Gymnema sylvestre- A medicinal plant. Plant Cell Tiss. Org. Cult. 61: 97105.

Murashige, T. and F. Skoog 1962. A revised medium for rapid growth and bioassys in tobacco tissue culture. Physiol. Plant 15: 473-497.

Nasib, A., K. Ali and S. Khan 2008. In vitro propagation of Croton (Codiaeum variegatum), Pak. J. Bot. 40(1): 99-104.

Omran, V.G., A. Bagheri and N. Moshtaghi 2008. Direct in vitro regeneration of Lentil (Lens culinaris Medik.). Pak. J. Biol. Sci. 11(18): 2237 2242.

Robinson, P., S.J. Britto and V. Balakrishnsn 2009. Micropropagation of Costus speciosus (Koem. ex.
Retz) Sm., an antidiabetic plant by using explants of pseudostems. Bot. Res. Intn. 2(3): 182-185.

Sasikumar, S., S. Raveendar, A. Premkumar, S. Ignacimuthu and P. Agastian 2009. Micropagation of Baliospermum montanum (Willd.) Muell. Arg.A threatened medicinal plant. Ind. J. Biotech. 8: 223-226.

Sharma, M.M., P. Khanna and A. Batra 2006. An efficient in vitro mass propogation of a medicinally potent plant species Vitex negundo L. via nodal segments. Phytomorph. 56(1-2): 35-39.

Thoyajasksha and R. Ravishankar 2001. In vitro micropropagation of Dictyospermum ovalifolium Wight. A rare endemic plant in Western Ghats India. Plant Cell Biol. Mol. Biol. 2: 57-62.

Thyagarajan, S.P., S. Subremanian, T Thirunalasundari, P.S. Venkateswaran and B.S. Blumberg 1998. Effect of Phyllanthus amàrus on chronic carriers of hepatitis B virus. Lancet 2: 764766.

Unander, D.W. 1998. Phyllanthus species: in vitro culture and production of secondary metabolites. In Biotechnology in agriculture and forestry (ed. Y.P.S. Bajaj), Springer-Verlag, Berlin. 37: 304318. 